\title{
EL NUEVO CÓDIGO PROCESAL PENAL (NCPP) DEL 2004, LA JURISDICCIÓN COMUNAL Y LAS RONDAS CAM PESINAS
}

\author{
J. Fernando Bazán Cerdán*
}

\begin{abstract}
Resumen
En el artículo se examina el proceso de implementación progresiva del Nuevo Código Procesal Penal aprobado en el año 2004 en el Perú, destacando el análisis del contenido y los alcances de su artículo $18^{\circ}$, que establece límites a la jurisdicción penal ordinaria para el conocimiento de hechos punibles, a partir del reconocimiento constitucional de la denominada jurisdicción especial indígena o jurisdicción comunal establecida en el artículo $149^{\circ}$ de la Constitución Política del Perú de 1993, que en definitiva suscitan diversas cuestiones entre la jurisdicción comunal y el reconocimiento legal de la atribución para resolver conflictos por las rondas campesinas, así como la generación de potenciales factores de conflictividad competencial entre la jurisdicción penal ordinaria y la justicia comunal.
\end{abstract}

Palabras clave: Código Procesal Penal - sistema de enjuiciamiento penal jurisdicción penal ordinaria - jurisdicción comunal - rondas campesinas.

\begin{abstract}
This article examines the process of the progressive implementation of the new Procedural Criminal Code approved in 2004 in Peru, emphasizing the analysis of content and reaches of its article $18^{\circ}$, which establishes the limits of the ordinary criminal jurisdiction for the knowledge of punishable facts from the constitutional recognition of the denominated indigenous special jurisdiction or communal jurisdiction established in the article $149^{\circ}$ of the Political Constitution of the Peru of 1993, that really provokes diverse questions between the communal jurisdiction and the legal recognition of the attribution to solve conflicts by the armed farmers, as well as the generation of potential factors of competential confliction between the ordinary criminal jurisdiction and communal justice.
\end{abstract}

Key words: Penal Procedural code - system of penal judgment - ordinary penal jurisdiction - communal jurisdiction - rounds farmers.

\section{Sumario}

1. Introducción. 2. Límites a la jurisdicción penal en el NCPP. 3. La jurisdicción comunal. 4. Las rondas campesinas 5 . Cuestiones sobre la jurisdicción comunal y las rondas campesinas. 6 . Factores de conflictividad competencial entre la jurisdicción penal ordinaria y a justicia comunal. 7. Colofón.

* Juez Especializado Titular de la Corte Superior de Justicia de Cajamarca - Poder Judicial de Perú. 


\section{INTRODUCCIÓN}

Actualmente el Perú viene dando los primeros pasos para reformar su sistema procesal penal, siguiendo el camino que en su oportunidad comenzaron a transitar muchos países de América Latina en los últimos tres lustros -tales como Puerto Rico, Chile, Colombia, etcétera-, aunque cada cual con sus propias particularidades, en términos de grados de compromisos institucionales de los actores, intensidades de voluntades políticas, montos de recursos aplicados, niveles de cualificación técnica de operadores jurídicos y resistencias al cambio cultural.

De esta manera, el 29 de julio del año 2004 y mediante el Decreto Legislativo $\mathrm{N}^{\circ} 957^{1}$ se promulgó el Nuevo Código Procesal Penal (NCPP), el cual en su Primera Disposición Final declaró un periodo de vacatio legis y estableció el carácter progresivo de su proceso de implementación en los diferentes distritos judiciales, de acuerdo a un calendario oficial. Así, el 01 de julio de 2006 el NCPP entró en vigencia en el distrito judicial de Huaura, el 01 de abril de 2007 comenzó su aplicación en el distrito judicial de La Libertad, el 01 de abril de 2008 se inició la implementación en los distrito judiciales de Tacna y Moquegua, y el 01 de octubre de 2008 en el distrito judicial de Arequipa ${ }^{2}$. Se espera que sucesivamente entre en vigencia en el resto de distritos judiciales del Perú, hasta culminar su aplicación progresiva con el distrito judicial de Lima.

Con el NCPP se proyecta reemplazar el modelo procesal penal inquisitivomixto vigente desde 1940, por un sistema acusatorio oral. Según el último Reporte de la Justicia del CEJA ${ }^{3}$, las principales críticas al actual sistema procesal penal se relacionan con su estructura inquisitiva y secreta, la asignación de funciones de investigar y juzgar en una misma persona, el carácter secreto de la investigación, el proceso burocrático, y el escaso contacto de acusados y víctimas con el Juez.

Por el contrario, las principales características del nuevo proceso penal reformado radican esencialmente en el abandono de la estructura inquisitiva y reservada; el otorgamiento de una nueva orientación basada en la igualdad de condiciones para las partes; la facultad del Ministerio Público para investigar los delitos que se cometan y dirigir la investigación policial; el derecho de defensa al imputado en un plano igualitario en el marco del debido proceso; y la instauración del juicio oral y público.

Asimismo, tal como también lo sostiene el aludido Reporte ${ }^{4}$, el proceso de implementación del nuevo ordenamiento procesal penal en el Perú, en términos 
de reforma estructural del actual sistema de justicia, implicará reordenar el sistema de enjuiciamiento penal y acercarse al ideal de justicia pronta y cumplida; potenciar el derecho a la defensa; y asegurar en lo posible la vigencia de los derechos humanos cuando el Estado haga valer su pretensión punitiva.

\section{LÍMITES A LA JURISDICCIÓN PENAL EN EL NCPP}

En la perspectiva del reordenamiento del sistema de justicia penal y de la aproximación al ideal de acceso generalizado a la justicia, que subyace al proceso de implementación progresiva del NCPP, resulta especialmente sugestivo y controversial intentar analizar el sentido y alcances de su artículo $18^{\circ}$, norma -aún no vigente en gran parte del país- que establecerá los límites de la jurisdicción penal ordinaria, en especial el referido al ejercicio del derecho humano a la función jurisdiccional por las comunidades campesinas y nativas (también denominado jurisdicción especial indígena o jurisdicción comunal). El artículo $18^{\circ}$ del NCPP establece lo siguiente:

“Artículo 18. Límites de la jurisdicción penal ordinaria.- La jurisdicción penal ordinaria no es competente para conocer:

1. De los delitos previstos en el artículo $173^{\circ}$ de la Constitución.

2. De los hechos punibles cometidos por adolescentes.

3. De los hechos punibles en los casos previstos en el artículo $149^{\circ}$ de la Constitución".

Sobre el particular, debe recordarse que, conforme a los artículos $16^{\circ}$ y $17^{\circ}$ del NCPP, la jurisdicción penal ordinaria o la potestad jurisdiccional del Estado en materia penal se extiende a los delitos y faltas, y será ejercida -como actualmente viene sucediendo en gran medida- por la Sala Penal de la Corte Suprema, las Salas Penales de las Cortes Superiores, los Juzgados Penales (constituidos en órganos colegiados o unipersonales), los Juzgados de la Investigación Preparatoria, y los Juzgados de Paz Letrados, con las excepciones previstas para los Juzgados de Paz.

Sin embargo, el artículo $18^{\circ}$ del NCPP establece los casos de excepción en que la jurisdicción penal ordinaria no será competente para conocer ciertos delitos y hechos punibles (delitos y faltas), estableciendo límites a su ejercicio. Se establecen tres excepciones al conocimiento de la jurisdicción penal ordinaria.

La primera excepción, está referida a los delitos de función cometidos por miembros de las Fuerzas Armadas y de la Policía Nacional, en cuya eventualidad son sometidos al fuero respectivo y al Código de Justicia Militar Policial, conforme a lo previsto en el artículo $173^{\circ}$ de la Constitución Política. 
La segunda excepción, esta vinculada a los hechos punibles cometidos por adolescentes infractores de la ley penal, conforme al tratamiento previsto en los artículos $183^{\circ}$ al $192^{\circ}$ del Código de los Niños y Adolescentes.

Finalmente, la tercera excepción se refiere a los hechos punibles en los "casos previstos" en el ejercicio de la función jurisdiccional por las comunidades campesinas y nativas, según lo establecido por el artículo $149^{\circ}$ de la Constitución Política del Perú (1993).

\section{LA JURISDICCION COMUNAL}

En este punto, es posible avizorar que este último límite o excepción a las competencias de la jurisdicción penal ordinaria, constituído por la denominada jurisdicción especial indígena ${ }^{5}$ o jurisdicción comunal, será el que mayores dificultades entrañará para su aplicación y efectiva vigencia en el marco del proceso de implementación progresiva del NCPP. Varias son las razones para prever dicho escenario futuro. Aproximarse a algunas de ellas nos permitirá conocer las causas que potencialmente podrían conspirar contra la necesaria implementación del NCPP y el adecuado respeto del ejercicio de la jurisdicción comunal, en ambos casos en regiones o distritos judiciales con presencia significativa de comunidades y población campesina y nativa, así como de rondas campesinas.

Para ello es preciso recordar el contenido del artículo $149^{\circ}$ de la Constitución Política del Perú, que a la letra establece que:

"Artículo $149^{\circ}$.- Las autoridades de las Comunidades Campesinas y Nativas, con el apoyo de las Rondas Campesinas, pueden ejercer las funciones jurisdiccionales dentro de su ámbito territorial de conformidad con el derecho consuetudinario, siempre que no violen los derechos fundamentales de las personas. La ley establece las formas de coordinación de dicha jurisdicción especial con los Juzgados de Paz y con las demás instancias del Poder Judicial."

Al respecto, de la interpretación del artículo $149^{\circ}$ de la Constitución Política del Perú de 1993, que reconoce la jurisdicción especial indígena o comunal, tal como lo sostiene Tamayo Flores ${ }^{7}$, se pueden desprender los siguientes elementos centrales para su configuración: 1) El reconocimiento de funciones jurisdiccionales a las autoridades de las Comunidades Campesinas y Nativas, con el apoyo de las rondas campesinas; 2) La potestad de dichas autoridades de ejercer tales funciones en su ámbito territorial; 3) La potestad de dichas 
autoridades para aplicar su derecho consuetudinario; 4) La sujeción de dicha jurisdicción al respeto de los derechos fundamentales; y 5) La competencia del Poder Legislativo para señalar las formas de coordinación de la jurisdicción especial indígena con el sistema judicial nacional.

Los tres primeros elementos conformarían el núcleo de autonomía otorgado a las Comunidades Campesinas y Nativas. Por su parte, los dos últimos elementos constituyen los mecanismos de integración de los ordenamientos jurídicos indígenas con el contexto del ordenamiento jurídico nacional ${ }^{89}$.

A pesar de lo indicado anteriormente, también se puede desprender que las relaciones entre la jurisdicción penal ordinaria y la jurisdicción comunal, entendida ésta como límite o excepción al ejercicio de las competencias de aquélla, no serán en modo alguno pacífico, aunque no necesariamente deben ser entendidas en términos de oposición sino de complementación dinámica. Tal situación se aprecia con meridana claridad del examen de la situación de las rondas campesinas con relación a la entrada en vigencia del NCPP en determinados distritos judiciales en los que resulta notoria su presencia, tales como La Libertad, Cajamarca, Piura, San Martín, Ancash, Puno, etc.

\section{LAS RONDAS CAM PESINAS}

En el Perú, junto al reconocimiento constitucional para ejercer funciones jurisdiccionales a las Comunidades Andinas y Amazónicas, desde aproximadamente tres décadas atrás han surgido y se han desarrollado otras formas de resolución de conflictos por parte de las organizaciones rurales denominadas Rondas Campesinas, que pueden ser definidas como organizaciones del campo, constituidas por decisión de los propios campesinos o vecinos de un sector, estancia o caserío, con el objeto de servir a su localidad en la lucha y la prevención de la delincuencia y la violencia.

\section{1. Historia}

Las Rondas Campesinas surgieron como organizaciones de autodefensa, con funciones básicas del cuidado de bienes y control del abigeato, ante la ausencia de las autoridades estatales o por su poca capacidad y legitimidad para resolver los conflictos sociales, a mediados de la década del 70 del siglo pasado en las provincias de Chota (Cuyumalca) y Bambamarca, del departamento de Cajamarca, al norte del Perú.

Es innegable que Cajamarca es la cuna de las rondas campesinas, las cuales encuentran sus antecedentes remotos en las guardias rurales de fines del Siglo 
XIX y en las rondas de hacienda de las primeras décadas del Siglo $X X^{10}$. Con variantes, la experiencia de las rondas campesinas se ha extendido hacia otras importantes zonas del país ${ }^{11}$.

Empero, actualmente no se cuenta con información precisa sobre su número, los asuntos y el modo en que resuelven los casos sometidos a su conocimiento, sin perjuicio de los múltiples estudios realizados sobre el particular. Sólo existen estimados no tan recientes que indicaban que a 1990 existían aproximadamente unas 3,435 organizaciones ronderas en el norte del Perú, correspondiendo a Cajamarca de dicho total la cantidad aproximada de 2,362 rondas campesinas ${ }^{12}$.

\section{2. Asuntos conocidos por las rondas campesinas}

En cuanto a los asuntos que conocen las rondas, enunciativamente se pueden mencionar en orden sucesivo de importancia: pleitos familiares, disputas por tierras, robos de bienes materiales (artefactos eléctricos, dinero, herramientas, etc.), daños por la entrada de animales a chacras ajenas, asaltos, robo de animales, deudas no pagadas, disputas por agua, difamación, robos de cosechas, violación, etc. ${ }^{13}$

Respecto a cómo resuelven los conflictos, se ha enfatizado su eficacia y la legitimidad social de sus decisiones, señalándose que resuelven a través de “...una búsqueda pragmática, no arbitraria de la decisión más adecuada. No se trata de la aplicación de normas, sino de un debate normativo, en el cual las normas forman el punto de partida...La discusión no son los hechos, que ya se toman por dados. El debate es cuál fue la causa del problema (...) Es una pelea sobre normas que provienen de diferentes lugares, a veces tradicionales, a veces de la ciudad, a veces de la televisión ${ }^{14}$."

Así, se sostieneque las rondascampesinas aplican“...una justicia reconciliadora que se basa en un debate normativo, en el que lo más importante es que los involucrados acepten su responsabilidad, pero no es solamente conciliatoria entre dos personas. También se busca la reconciliación con la comunidad, por ello es fundamental en el arreglo el reconocimiento de la organización de rond as o que la comunidad tiene el derecho de imponer normas. ¿Por qué es tan importante esto? Porque en el fondo, las rondas se basan fundamentalmente en esta convicción. Toda persona que no acepte lo que ha dicho la ronda, siempre tiene la posibilidad de ir al Estado y denunciar y la ronda siempre tiene el problema de imponer su autoridad. En tercer lugar la ronda debe manejar su relación con el Estado, que no necesariamente es una relación de enfrentamiento, pero siempre es difícil..$^{15 "}$ 
En este punto debe indicarse que, sin perjuicio de la constatación empírica de la existencia de las rondas campesinas y el dato fáctico respecto a que éstas ejercen mecanismos tradicionales de resolución de conflictos, tales aspectos no han tenido un correlato preciso con el reconocimiento normativo de las mismas y con la interpretación doctrinal sobre su rol de entes que asumen funciones de administración de justicia en el campo.

\section{3. Posiciones doctrinales}

Por su parte, las posiciones doctrinales al respecto se encuentran divididas, con diversos matices, entre los que sostienen que las rondas campesinas tendrían relativas facultades de colaboración en las funciones jurisdiccionales y policiales ${ }^{16}$; los que plantean que las rondas campesinas constituyen instancias informales de resolución de $\operatorname{conflictos}^{17}$; y quienes afirman que las rondas campesinas tienen y deben ejercer de manera plena funciones jurisdiccionales ${ }^{18}$.

De lo señalado anteriormente, se puede apreciar que no resulta pacífico el reconocimiento del innegable papel que cumplen las rondas campesinas en el ámbito de la resolución de conflictos y administración de la justicia. Esta situación se ha visto acrecentada en los últimos tiempos debido a los conflictos suscitados con los órganos de administración de justicia del Estado, en los que se ha evidenciado la resistencia de la cultura judicial formal, expresándose en argumentos que apuntan a negar el ejercicio de tales funciones jurisdiccionales, y que normativamente pueden ser válidas, tales como aquel argumento que sostiene que falta una ley reglamentaria (Ley de Coordinación) para aplicar el artículo $149^{\circ}$ de la Constitución; o aquel otro que afirma que las rondas campesinas no tienen la titularidad para ejercer funciones jurisdiccionales; o el argumento que postula que las autoridades de las comunidades sólo pueden actuar con apoyo de las rondas campesinas; que las rondas campesinas son sólo órganos de apoyo de las comunidades y no pueden actuar de modo autónomo; que la expresión "con apoyo" significa funciones restringidas de justicia, etc.

\section{4. La ley No 24571}

A pesar que la Constitución Política del Perú de 1979 no contempló expresamente la situación de las Rondas Campesinas, desde fines de 1986, año en que se promulgó la Ley $\mathrm{N}^{\circ} 24571$ que las reconoció ${ }^{19}$, el desarrollo legislativo experimentado por esta institución campesina se realizó bajo el manto de dicho cuerpo constitucional, que definió la obligación estatal de respetar y proteger la autonomía organizativa y las tradiciones de las Comunidades Campesinas y Nativas (Art. $161^{\circ}$ ). 
De esta manera, la Ley $\mathrm{N}^{\circ} 24571$ reconoció legalmente a las Rondas Campesinas, ya sea que pertenecieran o no a una Comunidad Campesina, como organizaciones autónomas de defensa al servicio de la comunidad o colectividad en general, con capacidad para cooperar con las autoridades en la eliminación de los ilícitos penales que afecten el orden interno, debiendo sujetarse a las normas constitucionales y civiles que regulan a las comunidades campesinas, y sus miembros estar acreditados ante la autoridad política competente, conforme se advierte de su único artículo:

"Artículo Único.- Reconózcase a las rondas campesinas pacíficas democráticas y autónomas, cuyos integrantes están debidamente acreditados ante la autoridad política competente, como organizaciones destinadas al servicio de la comunidad y que contribuyen al desarrollo y a la paz social, sin fines políticos partidarios.

Tienen además como objetivos, la defensa de sus tierras, cuidado de su ganado y demás bienes, cooperand o con las autoridades en la eliminación de cualquier delito.

$\mathrm{Su}$ estatuto y reglamento se rigen por las normas de las comunidades campesinas que establecen la Constitución y el Código Civil."

El Reglamento de la primera Ley de Rondas Campesinas se emitió en $1988^{20}$. En el año 1993 el referido Reglamento fue dejado sin efecto por una norma administrativa del sector defensa ${ }^{21}$.

A través de la Ley General de Comunidades Campesinas de 1987 (Ley N²4656) y en su primer Reglamento de $1991^{22}$, se reguló la constitución y naturaleza jurídica de las Rondas Campesinas, organizadas al interior de las comunidades campesinas, al establecer como atribución de la Asamblea Comunal aprobar su nacimiento e indicar su naturaleza de Comité Especializado de carácter consultivo, asesor, ejecutivo y de apoyo de la comunidad, dependiente de la Directiva Comunal de las comunidades campesinas.

\section{5. Las rondas campesinas y los comi tés de autodefensa ${ }^{23}$}

A partir de 1991, en el marco de la estrategia contra subversiva del Estado, se expidió el Decreto Legislativo $\mathrm{N}^{\circ} 741^{24}$ para regular las relaciones de los Comités de Autodefensa, entendiéndolas como un soporte estratégico en la lucha contra la subversión en el campo, y las instituciones del sistema de defensa nacional. Asimismo, se reconoció a las Rondas Campesinas, ubicadas dentro del ámbito territorial de las zonas en estado de emergencia, la posibilidad de adquirir y usar armas para apoyar a las fuerzas de seguridad 
en la situación de conflicto armado interno, así como convertirse voluntaria y transitoriamente en Comités de Autodefensa ${ }^{25}$, bajo la autorización y el control de las autoridades militares.

Lamentablemente, para las Rondas Campesinas la voluntariedad y libertad para su conversión en Comités de Autodefensa fue desnaturalizada con el D.S. $\mathrm{N}^{\circ}$ 002-93-DE/CCFFAA, al establecer su adecuación forzada y obligatoria a la mencionada forma organizativa de autodefensa promovida por las fuerzas de seguridad, sin tener sustento en norma legal alguna de mayor jerarquía ${ }^{26}$.

Desde el punto de vista histórico y normativo-funcional, las Rondas Campesinas se diferencian de los Comités de Autodefensa en que, las primeras, surgen para el combate de la delincuencia, el mantenimiento del orden interno y la resolución de conflictos comunales, son autónomas y permanentes y, las segundas, se originan para enfrentar a los grupos subversivos como parte de la estrategia estatal contrainsurgente, con el carácter de transitorios y dependientes de las Fuerzas Armadas.

\section{6. Las rondas campesinas y la jurisdicción especial indígena}

Tal como se ha señalado anteriormente, la Constitución de 1993, en su artículo $149^{\circ}$, bajo la configuración constitucional del Estado Peruano como una nación pluricultural y multiétnica, al regular el rol de las Rondas Campesinas, se afilió al espíritu de la regulación del instituto rondero contemplado en la Ley General de Comunidades Campesinas de 1987 y en cierta medida recogió la alusión a las Rondas Nativas del Reglamento de Organización y Funciones de los Comités de Autodefensa de 1992, puesto que reconoció su carácter de órganos de apoyo (auxilio) de las autoridades comunales -campesinas y nativas- en el ejercicio de sus funciones jurisdiccionales, dentro de su ámbito territorial, conforme a su derecho consuetudinario y con el límite de no violar los derechos fundamentales de las personas.

Sin embargo, del texto constitucional no aparece una mención expresa a las Rondas Campesinas organizadas fuera del ámbito de las Comunidades Nativas y de la Comunidades Campesinas, que, según la primera Ley de Rondas Campesinas de 1986, se rigen en lo que sea pertinente por la legislación de las comunidades campesinas -sin que por ello se conviertan en tales comunidades- y tienen como funciones esenciales la defensa de sus tierras, el cuidado de su ganado y demás bienes, así como la cooperación con las autoridades en la eliminación de cualquier delito. 
Aunque en la práctica la Rondas Campesinas vienen efectuando actividades que han desbordado el enfrentamiento al abigeato, tales como la realización de obras de infraestructura de interés para la comunidad, la vigilancia e intervención sobre conductas antisociales de manera amplia; normativamente se puede sostener, por un lado, que las Rondas Campesinas organizadas fuera del ámbito de las Comunidades Campesinas sólo tendrían relativas facultades resolutivas de conflictos de orden penal, en cooperación con las autoridades, $y$, de otro lado, que las Rondas Campesinas creadas al interior de las Comunidades Campesinas y Nativas tendrían facultades de apoyo para el ejercicio de las funciones jurisdiccionales por las autoridades comunales, las cuales se ampliarían a la directa administración de justicia y resolución de conflictos, en la medida que los dirigentes de este tipo de Comité Especializado formen parte -y no sean dependientes- de la Directiva Comunal de una Comunidad Campesina.

\section{7. Las rondas campesinas y los pueblos indígenas}

Teniendo en cuenta, por un lado, que el concepto normativo sobre los pueblos indígenas ha sido formulado y adoptado en el ámbito de los organismos internacionales multilaterales ${ }^{27}$ con el propósito de regular las medidas nacionales que puedan adoptarse y afectar la futura existencia de los indígenas en el ámbito de los Estados; y, por otro lado, que la conciencia de identidad indígena o auto identificación constituye un criterio fundamental para determinar los grupos e individuos a los que se aplica el concepto de indígena y las disposiciones normativas especiales dictadas en su beneficio; es posible concluir -objetivamente y para efectos operativos-, a pesar de que en gran medida el término indígena tiene una acepción peyorativa de carácter histórico para el sector campesino ubicado en la Costa y Sierra del Perú, que las Rondas Campesinas organizadas al interior de las comunidades campesinas pueden ser consideradas como grupos humanos asimilables al concepto de pueblos indígenas, en la medida que se auto identifiquen como tales.

Sin embargo, la situación de las Rondas Campesinas surgidas fuera de las comunidades -como es el caso de Cajamarca ${ }^{28}$, ya sea en los caseríos u otras formas de organización social y jurídica, se complica para efectos de reconocerles el estatus de pueblo indígena, en razón de no haber desarrollado suficientemente expresiones de auto identificación étnica, en tal sentido y considerando que el tratamiento normativo del instituto rondero se orientó hacia la aplicación supletoria de la legislación de las comunidades campesinas, a pesar de no tener la calidad de tales. 
Distinta es la situación de las Rondas Nativas y de los Comités de Autodefensa surgidas al interior de las Comunidades Nativas o conformadas con la participación de nativos pertenecientes a distintas comunidades, de manera espontánea o promovidas por el Estado, que histórica y objetivamente se han venido autoidentificando como indígenas, razón por la cual se puede afirmar que tales organizaciones de autodefensa y resolución de conflictos formarían parte de los pueblos indígenas.

\section{8. La ley $N^{\circ} 27908$}

Sin embargo, el contexto normativo interpretativo antes descrito, experimentó una variación sustancial con la promulgación de la nueva Ley $\mathrm{N}^{\circ} 27908$, Ley de Rondas Campesinas ${ }^{29}$ el año 2003, esencialmente en términos de incremento del reconocimiento de derechos para tales organizaciones sociales. Esta Ley de Rondas Campesinas fue reglamentada el 30 de diciembre del $2003^{30}$.

Preliminarmente, se puede afirmar, por un lado, que la nueva Ley de Rondas Campesinas constituye un significativo avance en cuanto al reconocimiento de personalidad jurídica y derechos a las organizaciones ronderas; $\mathrm{y}$, por otro lado, respecto al rol y funciones de las rondas campesinas en materia de justicia, presenta serias deficiencias en su consistencia interna, por la existencia de disposiciones contradictorias, regulación que al ser interpretada y aplicada a casos concretos es sumamente probable que debilite la institucionalidad de las rondas campesinas.

Entre las bondades de la Ley de Rondas Campesinas, se pueden mencionar la disposición según la cual se reconoce "...personalidad jurídica a las Rondas Campesinas como forma autónoma y democrática de organización comunal, ..." (Artículo $1^{\circ}$ ); los derechos y deberes de sus miembros (Artículo $3^{\circ}$ ); el derecho a la no discriminación (Artículo $4^{\circ}$ ); el derecho de participación, control y fiscalización en los programas y proyectos de desarrollo que se implementen en su jurisdicción comunal (Artículo $6^{\circ}$ ); la coordinación con autoridades y organizaciones sociales (Artículo $8^{\circ}$ ); la coordinación y apoyo con autoridades jurisdiccionales (Artículo $9^{\circ}$ ); etc.

De otro lado, en la Ley de Rondas Campesinas se enfatizan las funciones relativas a la seguridad (Artículo $1^{\circ}$ ), que en forma casi simultánea fueron contempladas por la Ley $\mathrm{N}^{\circ} 27933$ del 2003 y el Decreto Supremo N $^{\circ} 012-$ 2003-IN, relativos al sistema nacional de seguridad ciudadana, que a grandes rasgos vinieron a reafirmar la tendencia legislativa sobre el particular desde el año 1986. 
Sin embargo, la normativa de la Ley de Rondas Campesinas se complica en lo que se refiere al papel de las rondas campesinas ante la administración de justicia.

Así, en la línea de la posición doctrinal que sostiene que las rondas campesinas tienen relativas facultades de colaboración en el ejercicio de las funciones jurisdiccionales por parte de las comunidades, la Ley de Rondas Campesinas declara que, éstas "... apoyan el ejercicio de funciones jurisdiccionales de las Comunidades Campesinas y Nativas..." (Artículo $1^{\circ}$ ), postulado que, a su vez, resulta coherente con la disposición conforme a la cual donde existan comunidades las rondas están subordinadas a aquéllas (Artículo $2^{\circ}$ ).

Por su parte, afiliándose en forma prudente a la concepción que levanta el argumento de que las rondas campesinas configuran instancias informales de resolución de conflictos, encontramos otra formulación normativa en la Ley de Rondas Campesinas, según la cual las organizaciones ronderiles "... colaboran en la solución de conflictos y realizan funciones de conciliación extrajudicial conforme a la Constitución y la Ley..." (Artículo $\left.1^{\circ}\right)^{31}$.

De otro lado, acercándose aparentemente al planteamiento que propugna que las rondas campesinas tiene y ejercen de manera plena funciones jurisdiccionales, en la Ley de Rondas Campesinas se contempla que éstas tienen "...funciones relativas...a la paz comunal dentro de su ámbito terrritorial" (Artículo $1^{\circ}$ ). Este último aspecto es desarrollado por la misma norma legal al tratar las actividades en beneficio de la paz comunal, de la siguiente manera: "Las Rondas Campesinas en uso de sus costumbres pueden intervenir en la solución pacífica de conflictos suscitados entre miembros de la comunidad u organizaciones de su jurisdicción y otros externos, siempre y cuando la controversia tenga su origen en hechos ocurridos dentro de su jurisdicción comunal" $\left(\right.$ Artículo $\left.7^{\circ}\right)$.

Finalmente, la interpretación de las facultades y derechos atribuidos a las rondas campesinas, que han sido reseñadas en los tres párrafos anteriores, se ve perturbada en mayor medida con la fórmula contenida en la referida Ley de Rondas Campesinas, por la cual "Los derechos reconocidos a los pueblos indígenas y comunidades campesinas y nativas se aplican a las Rondas Campesinas en lo que les corresponda y favorezca" (Artículo $1^{\circ}$, in fine). 


\section{CUESTIONES SOBRE LA JURIDICCION COMUNAL Y LAS RONDAS CAMPESINAS}

En este nivel del análisis, resulta inevitable el surgimiento de diversas interrogantes sobre el sentido, significado y alcances del reconocimiento constitucional de la jurisdicción comunal y el rol de las rondas campesinas en la resolución de conflictos. Sin ningún orden especial se plantean las mismas.

A ¿Son las Rondas Campesinas instituciones equivalentes o comparten la misma naturaleza jurídica que las Comunidades Campesinas y Nativas, en términos históricos, sociales y jurídicos?

B. ¿Es posible aplicar y "transferir" derechos por mandato legal de un sujeto de derecho (Comunidades Campesinas y Nativas) a otro sujeto de derecho (Rondas Campesinas), el primero de los cuales tiene un plexo de derechos reconocidos constitucionalmente $\mathrm{y}$ en instrumentos internacionales, $\mathrm{y}$ a pesar que el segundo responde a una realidad histórica diferente y tiene una naturaleza jurídica particular?

C. ¿A partir de la vigencia de la Ley $\mathrm{N}^{\circ} 27908$, los derechos reconocidos a los Pueblos Indígenas y Comunidades Campesinas y Nativas se aplicarán únicamente a las Rondas Campesinas formadas y sostenidas al interior de las comunidades, a pesar que aquéllas no tendrían una personalidad jurídica autónoma y están subordinadas a las comunidades?

D. ¿A partir de la vigencia de la Ley $\mathrm{N}^{\circ} 27908$, los derechos reconocidos a los Pueblos Indígenas y Comunidades Campesinas y Nativas se aplicarán también a las Rondas Campesinas organizadas en los lugares donde no existan o no sean predominantes las comunidades, a pesar de que sus miembros no se identifiquen como indígenas o pertenecientes a pueblos indígenas?

E. ¿La atribución constitucional conferida expresamente a las autoridades de las Comunidades Campesinas y Nativas para ejercer funciones jurisdiccionales dentro de su ámbito territorial, también se extiende a las Rondas Campesinas en aplicación de la fórmula legal "...en lo que corresponda y favorezca", a pesar que la disposición constitucional sólo enuncie “...,con el apoyo de las Rondas Campesinas,..."?

F. ¿Ya sea en ejercicio de las funciones jurisdiccionales y/o de la potestad de intervenir en la solución pacífica de conflictos, reconocidas a las autoridades de las Comunidades Campesinas y Nativas y a las Rondas Campesinas, res- 
pectivamente, dicha organizaciones sociales tendrían competencia para conocer toda controversia que surja en su territorio (competencia territorial), sobre cualquier materia (competencia material) y respecto de cualquier persona (competencia personal)?

\section{FACTORES DE CONFLICTIVIDAD COMPETENCIAL ENTRE LA JURISDICCIÓN PENAL ORDINARIA Y LA JUSTICIA COMUNAL}

En función de lo indicado hasta este punto, deviene en necesario destacar algunos factores de posible conflictividad entre la jurisdicción penal ordinaria y la jurisdicción comunal, derivadas del ejercicio de sus específicos ámbitos competenciales. Entre ellos se puede mencionar algunas cuestiones pendientes de resolución:

6. 1. ¿Quién y cómo se define el contenido de las competencias (territoriales, materiales y personales) de la jurisdicción comunal?

6. 2. En el mismo sentido de las competencias materiales, ¿Qué hechos punibles (delitos y faltas) serán de conocimiento de la jurisdicción comunal?

6. 3. ¿Para definir los "casos previstos", aludidos en el numeral 3) del artículo $18^{\circ}$ del NCPP, constitutivos de hechos punibles, y sometidos a la jurisdicción comunal será requisito imprescindible la elaboración de estudios y registros etnográficos a nivel nacional sobre las formas y contenidos de los sistemas de resolución de conflictos de los grupos étnicos, pertenecientes o no a comunidades campesinas y nativas y sobre las formas de coordinación y relacionamiento con la jurisdicción ordinaria?

6. 4. En el procesamiento de hechos punibles por la jurisdicción comunal, ¿Qué mecanismos se deberán emplear para determinar los derechos fundamentales mínimos que deben respetarse para su ejercicio?

6. 5. Ante los posibles conflictos en el ejercicio de las competencias de ambas jurisdicciones, ¿Cuáles serán los contenidos de las formas de coordinación y cuáles los criterios de coordinación para resolver los conflictos surgidos al interior (entre miembros o no) o al exterior de la comunidad?

6. 6. En la eventualidad de conflictos jurisdiccionales, ¿La coordinación se justifica en temas de grave conflicto intercultural, en materia penal, o la coordinación sólo se justifica en materia civil, no siendo el ámbito penal objeto de coordinación? 
6.7. En los distritos judiciales en los que ha entrado en vigencia en su integridad el NCPP, ¿Para aplicar el artículo $18^{\circ}$ del NCPP, en el extremo referido al ejercicio de la jurisdicción comunal, resulta necesario exigir la previa aprobación por el Poder Legislativo de la Ley de Coordinación ${ }^{32}$ prevista en el artículo $149^{\circ}$ de la Constitución?

6. 8. En los distritos judiciales en los que ha entrado en vigencia en su integridad el NCPP, ¿El artículo $18^{\circ}$ del NCPP le resultaría aplicable a las Rondas Campesinas $^{33}$, en caso ellas existan y tengan reconocida su personalidad jurídica ${ }^{34}$, conforme a la Ley de Rondas Campesinas (Ley $\mathrm{N}^{\mathrm{0}}$ 27908)?

\section{COLOFÓN}

A modo de colofón, debe señalarse que del adecuado tratamiento que se brinde al tema de las relaciones entre la jurisdicción penal ordinaria y la jurisdicción comunal (específicamente en cuanto al contenido de su competencia en materia de hechos punibles y al rol de las rondas campesinas), establecida la segunda como límite o excepción al ejercicio de la primera, según lo prescrito audazmente por el artículo $18^{\circ}$ del NCPP, dependerá en gran medida el futuro reordenamiento del sistema de justicia penal en el Perú, que tiene como su baluarte al proceso de implementación progresiva del NCPP, y la materialización del hasta hoy abstracto derecho al acceso de la justicia en el ámbito penal para la población de zonas rurales del país.

1 Decreto Legislativo N 957, Promulga el Código Procesal Penal, de fecha 29 de julio del 2004. Ver: http://www.cajpe.org.pe/RIJ/bases/LEGISLA/peru/957.pdf

2 Equipo Técnico Institucional de Implementación del NCPP del Poder Judicial. Secretaría Técnica. Según el Decreto Supremo $\mathrm{N}^{\circ}$ 005-2007-JUS, se reprogramó el calendario oficial de implementación del NCPP. Ver: http://www.pj.gob.pe/CorteSuprema/ncpp/equipo.asp?opcion=prin

3 Reporte sobre el Estado de la Justicia en las Américas 2006-2007, CEJA, 3ra. Ed. Santiago, Chile: 2007. Ver: http://www.cejamericas.org/reporte/

4 Reporte sobre el Estado de la Justicia en las Américas 2006-2007, ídem.

5 Bazán Cerdán, J. Fernando. La jurisdicción especial indigena en la Constitución Política del Perú (1993). Instituto Nacional de Antropología y Pensamiento Latinoamericano. Seminario Internacional: Los Pueblos Indígenas en el Siglo XXI: Interculturalidad, Derecho, Justicia y Desarrollo. Buenos Aires: 30 de agosto - 03 de septiembre 1999.

Ver: http://cejamericas.org/doc/documentos/lajurisdiccionespecialindigena.pdf 


\section{J. Fernando Bazán Cerdán \\ El Nuevo Código Procesal Penal (NCPP) del 2004, \\ la jurisdición comunal y las rondas campesinas}

6 Con matices y mutatis mutandi, en el derecho comparado, se encuentran disposiciones vinculadas a la resolución de conflictos indígenas en el artículo $86^{\circ}$ de la Constitución Política de Panamá (1972); el artículo $66^{\circ}$ de la Constitución Política de la República de Guatemala (1985, reformada en 1993); el artículo $89^{\circ}$ de la Constitución Política de la República de Nicaragua (1986); los artículos $109^{\circ}, 231^{\circ}$ y $232^{\circ}$ de la Constitución de la República Federativa del Brasil (1988); el artículo $246^{\circ}$ de la Constitución Política de Colombia (1991); el artículo $63^{\circ}$ de la Constitución de la Republica del Paraguay (1992); el artículo $54^{\circ}$ de la Ley $\mathrm{N}^{\circ} 19.253$, Ley Indígena de Chile (1993); el artículo 171 de la Constitución de Bolivia (1994); el inciso 17) del artículo $75^{\circ}$ de la Constitución de la República Argentina; el artículo 191º de la Constitución de Ecuador (1998); el artículo $260^{\circ}$ de la Constitución de la República Bolivariana de Venezuela (1999), y el artículo $2^{\circ}$, letra A, de la Constitución de México (1917, reformada 2001).

7 Tamayo Flores, Ana María. Balance y Perspectivas de la Jurisdicción Indígena y el Derecho Consuetudinario, a partir del contexto de Vulnerabilidad que enfrentan los Pueblos Indígenas Amazónicos. (Documento de Trabajo), Julio de 1997. En: Nosotros y los Otros. Avances en la afirmación de los pueblos indígenas amazónicos. Serie Informes Defensoriales. Informe N 12. Defensoría del Pueblo. Lima: agosto 1998. Pág. 193.

8 Bazán Cerdán, J. Fernando. El Estado del arte del derecho consuetudinario: El caso del Perú. Instituto Interamericano de Derechos Humanos (IIDH). En Revista $N^{\circ} 41$, Especial sobre Derecho Indígena (EneroJunio 2005). Costa Rica. Ver:

http://www.iidh.ed.cr/Publicaciones/Revista41/Derecho\%20indigena.pdf

9 Tamayo Flores, Ana María. ídem.

10 Pérez Mundaca, José. Montoneras, Bandoleros y Rondas Campesinas. Violencia política, abigeato y autodefensa en Cajamarca, 1855-1990. Municipalidad Provincial de Cajamarca, ASODEL y CEDEPAS. Cajamarca: 1997. Pág. 221.

11 Márquez Calvo, Jaime. Rondas y Comités de Autodefensa: Historia y Desarrollo. En: Ronderos: Los ojos de la noche. Manual para Promotores de Rondas Campesinas. 2da. Ed. Revisada. Instituto de Defensa Legal. Febrero, 1997.

12 Starn, Orin. Con los llanques todo barro: Reflexiones sobre Rondas Campesinas, Protesta Rural y Nuevos Movimientos Sociales. Instituto de Estudios Peruanos. Lima: 1991. Pág. 15.

13 Starn, Orin. op. cit. p. 43.

14 Gitliz, Jhon. Rondas Campesinas y Violencia. En: Justicia y Violencia en las Zonas Rurales. La experiencia de la Región Andina. Seminario - Taller. Lima, 20 a 22 de noviembre del 2002. Instituto de Defensa Legal - Internationale Weiterbildung und Entwicklung gGmbH. Lima, 2003. Pág. 146.

15 Gitliz, Thon. Op. Cit. pp.146-147.

16 Rojas Vargas, Fidel. Rondas Campesinas: entre el Derecho consuetudinario y el error de comprensión culturalmente condicionado. En: Estudios de Derecho Penal. Doctrina y Jurisprudencia. Jurista Editores E.I.R.L. Lima, 2004. Págs. 95-106.

Revilla, Ana Teresa. La administración de justicia informal en el Perú. Organización de Estado Americanos, Departamento de Asuntos y Servicios Jurídicos, Ver:

http://www.oas.org/Juridico/spanish/adjusti8.htm

17 Revilla, Ana Teresa. La administración de justicia informal en el Perú. Organización de Estado Americanos, Departamento de Asuntos y Servicios Jurídicos, Ver:

http://www.oas.org/Juridico/spanish/adjusti8.htm

18 Yrigoyen Fajardo, Raquel. Hacia un reconocimiento pleno de las rondas campesinas y el pluralismo legal. En: Revista Alpanchis: Justicia Comunitaria en los Andes. Nº59-60 Edición Especial, Vol. 1. Sicuani, Cusco: 2002, Instituto de Pastoral Andina. Págs. 31-81. Ver: http://alertanet.org/ryf-alpanchis.htm

19 Ley N ${ }^{\circ} 24571$, Ley de Reconocimiento de las Rondas Campesinas (07.11.86).

20 Decreto Supremo No 012-88-IN (12.03.88), Reglamento de Organización y Funciones de las Rondas Campesinas, Pacíficas, Democráticas y Autónomas.

21 Decreto Supremo No 002-93-DE/CCFFAA (16.01.93), dispone que las Rondas Campesinas adecuen su organización y funciones a las de los Comités de Autodefensa.

22 Decreto Supremo No 008-91-TR (15.02.91), Reglamento de la Ley General de Comunidades Campesinas. Artículo $69^{\circ}$ y $73^{\circ}$.

23 Ver: Resolución Defensorial N 55-DP-2000 (09.11.00). Expresan reconocimiento por la labor de las Rondas Campesinas y Comités de Autodefensa en la lucha contra el terrorismo y el restablecimiento del orden y la paz nacional. Diario Oficial El Peruano - Normas Legales. Págs. 194797-194799.

24 Decreto Legislativo $N^{\circ} 741$ (12.11.91), Ley de Reconocimiento de los Comités de Autodefensa. Artículos $1^{\circ}$, $2^{\circ}$ y $3^{\circ}$. 
25 Decreto Supremo N ${ }^{\circ}$ 077-92-DE, Reglamento de Organización y Funciones de los Comités de Autodefensa (11.11.92).

26 Ver: Situación de los Derechos Humanos en Jaén, Bagua y San Ignacio. Serie Informes Defensoriales Nº 31. Lima: Defensoría del Pueblo, diciembre 1999. Pág. 26.

27 Convenio N ${ }^{\circ} 169$ de la OIT sobre Pueblos Indigenas y Tribales en Países Independientes (1989) fue ratificado por el Perú mediante Resolución Legislativa No 26253 del 26 de diciembre de 1993. Este instrumento jurídico entró en vigor - para nuestro derecho interno- a los 12 meses del depósito del registro ante la OIT, vale decir, a partir del 02 de febrero de 1995. El Convenio $\mathrm{N}^{\circ} 169$ de la OIT sustituyó al anteriormente vigente Convenio $\mathrm{N}^{\circ} 107$ de la OIT. En cuanto al Convenio $\mathrm{N}^{\circ} 107$ de la OIT, denominado Convenio relativo a la Protección e Integración de las Poblaciones Indígenas y de otras Poblaciones Tribuales(sic) y Semitribuales(sic) en los Países Independientes (1957), fue aprobado por el Congreso peruano a través de la Resolución Legislativa N 13467 del 18 de noviembre de 1960.

28 Según información contenida en el Directorio de Comunidades Campesinas del Perú. PETT. Ministerio de Agricultura (Información a diciembre de 1998), en la región Cajamarca existen 107 comunidades campesinas reconocidas, de las cuales 78 están debidamente tituladas. Del total anterior, las comunidades campesinas se distribuyen por provincias, en atención a su reconocimiento legal (RL) y titulación (T), de la siguiente manera: Chota, 11 RL y 7 T; Cutervo, 7 RL y 5 T; Hualgayoc, 5 RL y 5 T; Santa Cruz, 5 RL y 4 T; Cajabamba, 7 RL y 4 T; y Cajamarca, 34 RL y $24 \mathrm{~T}$.

29 Ley $\mathrm{N}^{\circ}$ 27908, Ley de Rondas Campesinas (07.01.03).

Ver: http://www.mininter.gob.pe/article/articleview/1089/1/26/

30 D. S. N N $^{0}$ 25-2003-JUS, aprueba el Reglamento de la Ley de Rondas Campesinas (30.12.03).

31 La conciliación extrajudicial está regulada en nuestro país por la Ley $\mathrm{N}^{\circ} 26872$, Ley de Conciliación (13.11.97). El Nuevo Reglamento de la Ley $N^{\circ} 26872$, Ley de Conciliación fue aprobado por D. S. $N^{\circ} 004-$ 2005-JUS (27.02.05).

32 Bazán Cerdán, J. Fernando. La Ley de Coordinación entre la Justicia estatal y comunal: retos para la efectividad del Art. $149^{\circ}$ de la Constitución Política del Perú. Lima: Servindi, abril 2008. Ver: http://www. servindi.org/archivo/2008/3758

33 Bazán Cerdán, J. Fernando. Rondas campesinas: La otra justicia. Comisión Andina de Juristas. Proyecto Auditoria Social al Sistema de Justicia. Lima: marzo 2006. Ver:

http://www.auditoriajudicial.org.pe/pdfs/F_BAZAN_C-RONDAS_CAMPESINAS-LA_OTRA_ JUSTICIA-270406.pdf

34 Decreto Legislativo $N^{\circ}$ 957, promulga el Código Procesal Penal, de fecha 29 de julio del 2004 Ver: http://www.cajpe.org.pe/RIJ/bases/LEGISLA/peru/957.pdf 